\title{
Whole Health in the Whole System of the Veterans Administration: How Will We Know We Have Reached This Future State?
}

\author{
Tracy Gaudet, MD and Benjamin Kligler, MD, MPH
}

\begin{abstract}
Editor's Note: In the early years of whole systems research in integrative health, who imagined 15 years down the road that we would be looking at an effort to transform the whole system of the Veterans Administration (VA) with two longtime integrative health leaders piloting the initiative? This special issue is to separately publish "What Should Healthcare Systems Consider When Implementing Complementary and Integrative Health: Lessons from Veterans Health Administration." We invited this commentary as a companion piece on the context of the VA's "whole health" model in which that work is imbedded. Specifically, research is needed to show that in fact the system had reached what the authors call this "future state." Lead author Tracy Gaudet, MD, spent 15 years leading integrative initiatives at the University of Arizona College of Medicine and then Duke University Medical School before being tapped in 2011 as the founding director of the VA Office of Patient Centered Care and Health System Transformation. In 2015, Ben Kligler, MD, MPH - an integrative leader at the Society of Teachers of Family Medicine starting in the late 1990s, a driver of such initiatives at Albert Einstein School of Medicine and past chair of the Academic Consortium for Integrative Medicine and Health—joined Gaudet in 2015 as director of the VA's Integrative Health Coordinating Center. Kligler is also a coauthor on the article in this issue entitled "What Should Health Care Systems Consider When Implementing Complementary and Integrative Health: Lessons from Veterans Health Administration." It is our honor here at JACM to publish each of these two guiding documents for whole system change. -John Weeks, Editor-in-Chief
\end{abstract}

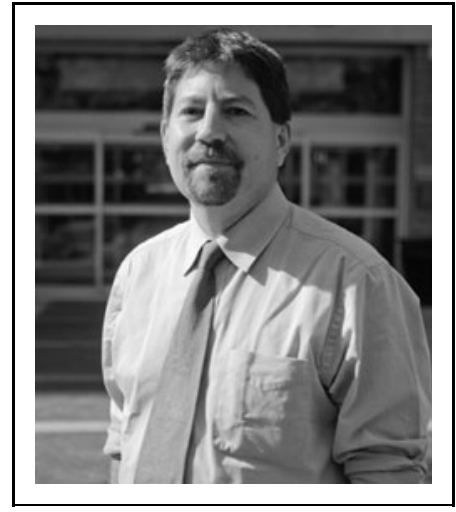

Ben Kligler, MD, MPH Office of Patient Centered Care and Cultural Transformation Veterans Health Administration Washington, DC

$\mathbf{I}_{\top}^{\mathrm{N}}$ N the Office of Patient Centered Care and Cultural Transformation at the U.S. Veterans Health Administration (VA), we refer to success as the "future state" of the VA. This future state will reflect a radical reorientation from a strictly disease-oriented system to one based in "health creation." 1 In our research and evaluation, this transformation will require us to look beyond endpoints typically measured as reductions of indications of disease to make measurement of well-being a primary outcome for the system. In fact, the declared emphasis for the entire VA system is "well-being and independence throughout [a veteran's] life

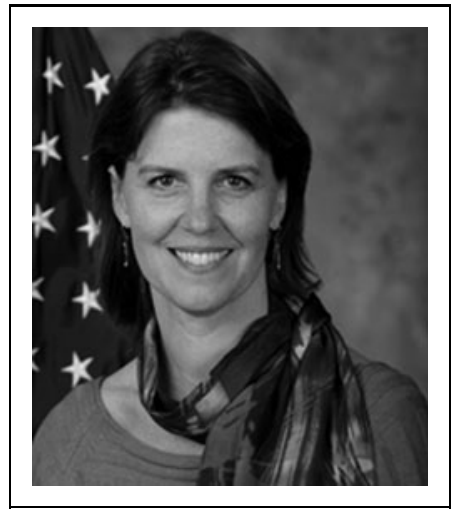

Tracy Gaudet, MD

Office of Patient Centered Care and Cultural

Transformation

Veterans Health

Administration

Washington, DC

journey." 2 To reach this goal, we are rallying around a "whole health" strategy, reaching toward practices that address the whole person including family, community, and social determinants of health to achieve this "future state."

But what are the measures and tools to achieve it? By what outcomes will we know when we arrive? We need to be asking these questions now to arrive at a system of veteran engagement that is truly focused on the outcomes of health and well-being.

First, some context. There are 19.5 million veterans in the United States. More than 9 million are served each year by 
the Department of Veterans Affairs. The delivery system includes 1,061 outpatient sites and almost 170 VA Medical Centers. The 2019 budget approaches $\$ 200$ billion. Administratively, service delivery is provided through 18 separate geographically defined networks. Our whole health strategy is presently being piloted in facilities in each of the 18 networks.

\section{A Radical Design for Health Care}

We take some of the inspiration for our model from Donald Berwick, the Institute for Healthcare Improvement cofounder and former administrator for the Center for Medicare and Medicaid Services. Berwick and colleagues called on leaders of the nation's hospitals and medical delivery organizations to engage "new rules for radical redesign of health care." 3 This followed his call for a 30-year refocus on "health creation" or "salutogenesis.",

A personal story that Don Berwick shared at the 2011 IOM Summit on Integrative Medicine and the Health of the Public also informed our model. As Dr. Berwick described his need to have surgery, and his own exploration about why he was doing this, and what "really, really, REALLY mattered to him," he shared his reflection that not one of his health care providers knew about him that it was his desire to have time with his grandchild. And yet this was his motivation for not only having the surgery, but for making a full recovery. ${ }^{5}$ So what would health care look like if we began with this exploration-and connecting with what motivates one toward health became the foundation of every person's health care? How could we design for this? The shift from a focus on limiting disease to one that creates health is less of a "redesign" than an act of creation of its own dramatic reorientation of priorities and how we measure them.

Fortunately, in our government-funded framework at the VA, some characteristics of this health-creating environment are built in. Our clinical services, for instance, are embedded in a network of family and community through which we can address other determinants of health. The VA's charge reaches beyond clinical walls. What we call the "Big VA"—our overarching organization-engages factors powerfully related to whole health outcomes such as housing, homelessness, education, and employment. Although we have our own interior silos, payment from a single source limits some of the challenges in the private payer environment in civilian medicine. Although it is true that these components are not optimally integrated toward our goals, the VA's broad vision of responsibility already begins to provide a whole health framework.

\section{Total Rewiring of Health Care}

The core of this paradigm shift toward whole health is in how we are trying to operationalize truly "patient-centered"

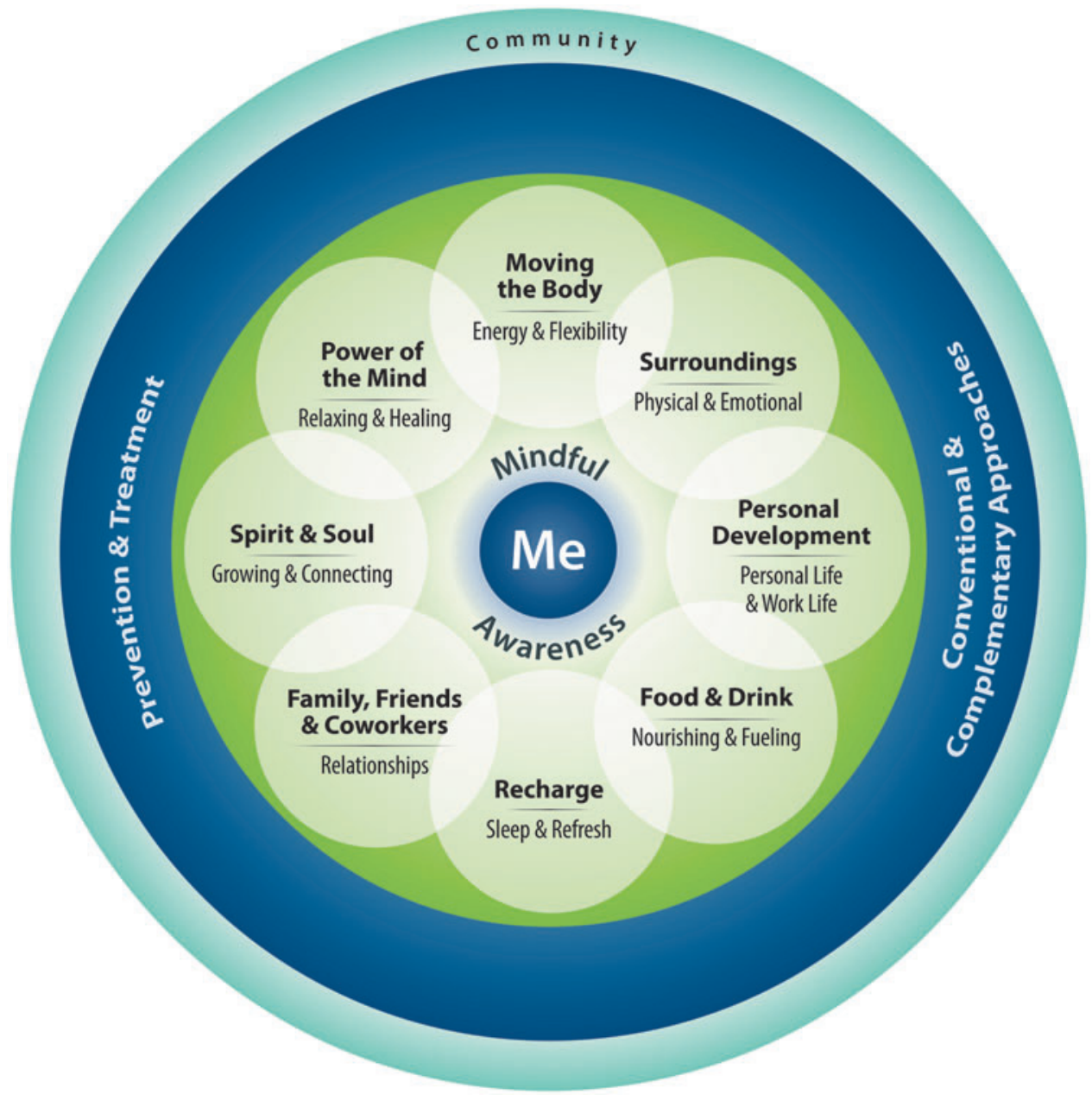


care. We begin by shifting the language from "patientdriven" to "person driven." 6 Supporting the well-being of veterans as human beings means moving beyond their conceptualization of themselves as "patients." The message is also that veterans are not merely passive recipients of treatment. Success requires that they be self-activated toward their own health. We start with a large-scale project to develop an infrastructure to support peer conversations between the veterans and their fellow veterans about what is important to them. Finding their passions-whether it is to get on their knees to play with their grandchildren or lose enough weight to ride in a roller coaster or be at peace enough to watch a sunset and enjoy it-fuels their health activism. We considered primarily using health coaches to support these peer-topeer conversations, but it quickly became clear that we have neither the budget nor a health coaching infrastructure well enough developed to meet the needs of our veterans and their families. As the next step, we developed an 8-week circle of health $^{7}$ program to support the peer-based operation. Peers have now been trained in every facility and are offering both a 2-hour introduction to whole health and the full peer program, Taking Charge of My Life and Health.

It is important to note that this initiative is based, by choice, in communities or nonclinical settings. They are also supported now in many VA facilities by well-being programs where the focus is on skill building and support for the changes that veterans wish to make. Whole health coaches as well as integrative health practitioners are an essential part of enabling that individual's self-care and their ability to move toward what matters to them in their life. The well-being programs as they develop will include nonpharmacologic mind and body educational and clinical services such as yoga, t'ai chi, acupuncture, massage, and chiropractic. ${ }^{8}$ These programs are supported by the Integrative Health Coordinating Center, a group established in 2014 within the Office of Patient Centered Care and Cultural Transformation to develop policy and build infrastructure across the Veterans Health Administration system for expansion of complementary and integrative health services. Some of these are delivered in group settings where forms of peer support continue; others require a more individual approach. Notably, many of these require a higher level of patient activation than regular treatment. These are substantially the focus of the other VA article in this special issue (see Taylor et al.).

Finally-and this is a critical aspect-these peer-based and well-being initiatives are connected to the VA's excellent network of practitioners in our outpatient and inpatient clinical treatment facilities, who are also being trained in the whole health approach. Primary care, mental health, rehabilitation medicine, nursing, social work, chaplaincy, and many other parts of the existing VA system are fully engaged with the whole health initiative. When the whole system is operational, the vision is that the veterans they are seeing can be clear about their mission and what they want their health for, are engaged in self-care practices, and that the clinical team and the veteran are working together from their personal health plan.

As should be evident by now, this is not a quick fix or a small or even large programmatic change. ${ }^{9,10}$ It is an effort to transform the culture of the VA system and to totally rewire what health care is and how it works.

\section{Measuring Success}

A truism in medicine and heath is that we get what we measure. So, if we are seeking new health-focused outcomes, we need to rethink what we measure. The VA has declared for the importance of well-being as an outcome in its 2018-2024 strategic plan. ${ }^{2}$ But although the plan includes an explicit commitment to measure this outcome, the exact strategy for doing that remains unclear. This challenge is not unique to the VA process, either. The National Institutes of Health's Pain Collaboratory with the U.S. Department of Defence and the VA, charged with forwarding strategies for management of chronic pain, recently held a video workshop nominally focused on integrative medicine's role in whole health. But the conversation quickly turned to mechanism of action and strategies such as micropharmaceuticals: in health care research, as everywhere, we tend to stay with what we know how to do.

We default to measure what we are familiar with and are routinely able to measure. Because the primary conceptual framework of medicine is disease oriented, medical research generally focuses on the notion of deficits. We have a conception of normal function and decrements off that, and because our clinical approach relies on this, we have welldeveloped tools for measuring those decrements and how a given intervention does or does not change them. We are not typically looking at well-being or positive outcomes. We ask how much pain people are in, but not how good they feel in their bodies. We try to determine how depressed people are, but not how happy or fulfilled they are. At best, the patient gets back to the zero state, where the deficit is gone.

If we are aiming at health creation though-beyond the zero state of "no disease" and forward to the state of aspiration and potential- how will we know if we are making progress? Developing the right measurement approaches for the possible outcomes of the whole health model is a critical next step. How do we test the rewiring of the system to see whether it is working? If one outcome we seek for veterans is life-long well-being, should we be putting more emphasis on measuring positive emotions in daily living? On life meaning and purpose? On the quality of relationships? Do we ask them whether they feel more engaged and activated in their lives and toward their health? Do they have new self-care skills? Mary Tinetti's work out of Yale offers some guidance as the whole health model has a strong connection to goal-aligned care. ${ }^{11,12} \mathrm{We}$ will need to measure whether we are making these alignments. These kinds of questions, of course, cast doubt on whether a randomized trial is the way to understand the benefits. And how do we measure our efforts to train our clinical staff in this new approach? We are working to support veterans who feel and live from a more self-empowered position - in health and in life. Do we need to identify a core competency for clinicians in taking care of people and supporting them that goes beyond offering clinical services-and then measure that?

\section{Measuring System-Level Transformation}

Measuring system-level transformation-as opposed to transformation on the individual level—requires a different set of process-oriented measures that will also differ from those the system typically uses. For instance, are the VA's divisions working on other determinants-homelessness or 
social isolation, for instance-coordinating better with those providing the same veteran's clinical services? We will want to monitor a combination of things such as social isolation and homelessness that are important at face value but also predictors of broad outcomes. How do we assess the systemlevel impact of the peer led Taking Charge of My Life and Health program and continuously refine this core program to foster engagement? How do we accurately assess the impact of the work of our whole health peers and coaches - new roles in the VA that challenge the traditional clinician-centric power structure-on the systems they work in? Obviously qualitative strategies will be an important part of this systems-level outcome assessment - but given the scale of the VA and the scope of the initiative, how can we make those qualitative approaches relevant to the entire system?

Transforming clinician perspectives toward whole health and well-being is another area that will benefit from improvement research. The VA is a system with a high burden of illness. Care is illness focused, and related research is often absorbed in that. Although we have not formally surveyed this, our guess is that many VA clinicians likely believe that well-being is something that may be applicable to only a lucky few of their patients. Most likely believe that for $80 \%-90 \%$ of patients, any idea of wellness comes down to whether the physicians, for instance, can fix a major medical problem. The baseline assumption is likely that wellness and well-being are a luxury only for patients who do not have something "real" going on. Our success in changing this perspective among some large proportion of VA clinicians will be a critical intermediate step in the success of the model. How will we measure that transformation?

\section{Measuring Clinician Well-Being}

A key element of the whole health strategy is also to directly address the well-being of clinicians, and of all employees. Bringing the whole health approach to all 330,000 VA employees is a tremendous challenge, but one we are working toward with high level support from VA leadership. We believe real transformation will not happen unless clinicians, administrators, and other employees experience this approach in their own lives. In this area, we have an opportunity to build on a strong commitment the VA has had in the past to measuring employee burnout and engagement. But there again these tend to be deficit-oriented measurement strategies. We will need to think creatively about how to measure purpose and meaning in our clinical staff as they experience more of the whole health approach in their own lives.

And what about measuring the change that may take place in how clinicians conceive of their role as this shift moves forward? How will we know that our clinicians better understand that whole health means reimagining the centrality of their services in meeting that second goal of the VA's strategic plan? We may wish to measure clinician rethinking-learning that a person at any stage of medical distress can have multiple relationships to their experience of wellness and well-being. Transformation urges us toward research on a better understanding of how people make health-related decisions, and what the role of their health care team is or should be in that process. How can clinical encounters and community-based resources better support engagement of behavioral determinants-nutrition, exercise, stress, relationships, and sleep? And will we be able to measure if a shift in resources is taking place-away from clinical care toward successful engagement with other determinants and with self-care, so that need for clinical service is limited? Fundamentally, how will we measure true cultural transformation? How will we know that VA has reached the future state?

From the vantage point of the VA's needs, and in the broader context of the call of Berwick and others toward a multiyear march of the medical industry to become a true health care system, it is possible that the whole system research conversation of 20 years ago was the right conversation, ahead of its time. Perhaps that conversation's time of latency is over. What is certain is that we need to be putting new thinking and new research resources behind new kinds of questions if we are to effectively assess the outcomes of this new/old approach to health.

\section{Author Disclosure Statement}

No competing financial interests exist.

\section{References}

1. Krejci LP, Carter, K, Gaudet T. Whole health: The vision and implementation of personalized, proactive, patient-driven health care for veterans. Medical Care 2014;52:S5-S8.

2. USA Department of Veteran's Affairs. Department of Veterans Affairs FY 2018-2024 Strategic Plan. Online document at: https://www.va.gov/oei/docs/VA2018-2024strategicPlan .pdf, accessed December 4, 2018.

3. Institute for Healthcare Improvement, IHI Leadership Alliance. New Rules for Radical Redesign of Health Care. Online document at: www.ihi.org/Engage/collaboratives/ LeadershipAlliance/Documents/IHILeadershipAlliance NewRulesRadicalRedesign.pdf, accessed December 4, 2018.

4. Weeks J. Hooking Up: Don Berwick, Integrative Medicine and His Call for a Radical Shift to 'Health Creation'. The Huffington Post 2014. Online document at: https://www .huffingtonpost.com/john-weeks/don-berwick-integrative-m_ b_4781105.html, accessed December 4, 2018.

5. Schultz AM, Chao SM, McGinnis MJ. Integrative Medicine and the Health of the Public: Summary of the February 2009 Summit. National Academy of Medicine, 2009. Online document at: http://nationalacademies.org/hmd/Reports/ 2009/Integrative-Medicine-Health-Public.aspx, accessed December 4, 2018.

6. Shulkin DJ. Beyond the VA crisis-Becoming a highperformance network. N Engl J Med 2016;374:1003-1005.

7. Department of Veterans Affairs. Whole Health for Life: Components of Proactive Health and Wellbeing. Online document at: https://www.va.gov/patientcenteredcare/explore/ about-whole-health.asp, accessed December 4, 2018.

8. Kligler B, Bair MJ, Banerjea R, et al. Clinical policy recommendations from the VHA state-of-the-art conference on non-pharmacological approaches to chronic musculoskeletal pain. J Gen Intern Med 2018;33:16-23.

9. Gaudet T. The Radical Redesign of Healthcare: The Why, What and How. Recorded presentation at the International Congress on Integrative Medicine and Health, Baltimore, Maryland, May 9, 2018. Academic Consortium for Integrative Medicine and Health. Online document at: https:// 
s3.amazonaws.com/imconsortium/AnMeeting/2018NarSlide Video/SK1ATK1b.mp4, accessed December 4, 2018.

10. Weeks J. Integrative Medicine Leader Tracy Gaudet and Her "Aha!" Moments Driving the VA's Cultural Transformation. Today's Practitioner, 2018. Online document at: www.johnweeks-integrator.com/uncategorized/integrativemedicine-leader-tracy-gaudets-aha-moments-driving-the-vascultural-transformation/, accessed December 4, 2018.

11. Naik AD, Dindo LN, Van Liew JR. Development of a clinically feasible process for identifying individual health priorities. J Am Geriatr Soc 2018;66:1872-1879.

12. Blaum CS, Rosen J, Naik AD, et al. Feasibility of implementing patient priorities care for older adults with multiple chronic conditions. J Am Geriatr Soc 2018;66: 2009-2016.

Address correspondence to: Benjamin Kligler, MD, MPH Office of Patient Centered Care and Cultural Transformation

Veterans Health Administration

810 Vermont Ave NW

Washington DC 20420

E-mail: benjamin.kligler@va.gov 